\title{
Adenosine stress and rest T1-mapping differentiates ischemic, infarcted, remote and normal myocardium - a novel gadolinium-free method for ischemia detection with immediate applications in coronary artery disease
}

\author{
Alexander Liu*, Rohan S Wijesurendra, Jane M Francis, Matthew D Robson, Stefan Neubauer, Stefan K Piechnik, \\ Vanessa M Ferreira
}

From 19th Annual SCMR Scientific Sessions

Los Angeles, CA, USA. 27-30 January 2016

\section{Background}

In stable coronary artery disease (CAD), accurate ischemia detection enables targeted revascularization, which improves clinical outcomes. Myocardial blood volume (MBV) may be a better ischemia marker than myocardial blood flow. Adenosine stress and rest T1-mapping is a novel gadolinium-free CMR technique that reflects changes in MBV through its water content. We hypothesized that different myocardial tissues in CAD patients and controls have distinctive T1-responses to adenosine, enabling ischemia detection without gadolinium agents.

\section{Methods}

CAD patients $(\mathrm{n}=13,65 \pm 10$ yrs, $>50 \%$ angiographic luminal stenosis in $\geq 1$ coronary artery) and normal controls $(\mathrm{n}=14$, with $\mathrm{n}=7: 28 \pm 5$ yrs and $\mathrm{n}=7: 57 \pm 13$ yrs $)$ underwent CMR at 1.5T to assess for LV function (cine), ischemia (adenosine stress/rest first-pass perfusion) and viability (late gadolinium enhancement, LGE). These were compared with novel adenosine stress/rest T1-mapping performed using ShMOLLI. T1 values of different myocardial tissues (infarcted, ischemic and remote in CAD patients; normal segments in controls) were estimated using manually placed regions of interest (ROI). ROI for infarcts were placed in the infarct core, carefully referenced to LGE and cine. ROI for ischemic myocardium were placed in regions corresponding to reversible perfusion defects on first-pass imaging, downstream significant

OCMR, University of Oxford, Oxford, UK 

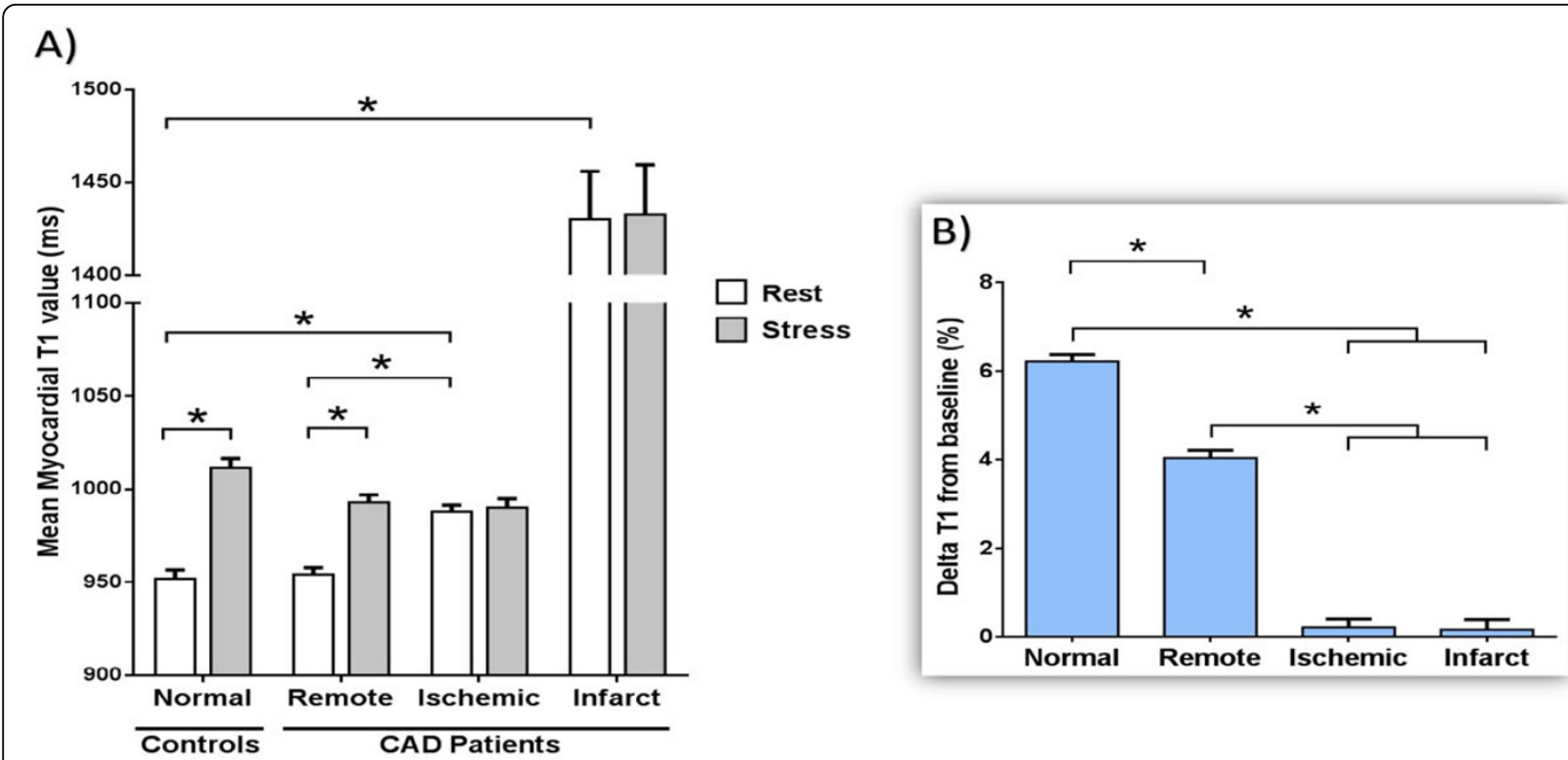

Figure 1 Normal, remote, ischemic and infarcted myocardial tissues demonstrate characteristic T1-profiles (A) and stress T1-responses (B). All bars represent mean \pm 1 SEM. ${ }^{*}$ denotes $p<0.001$.

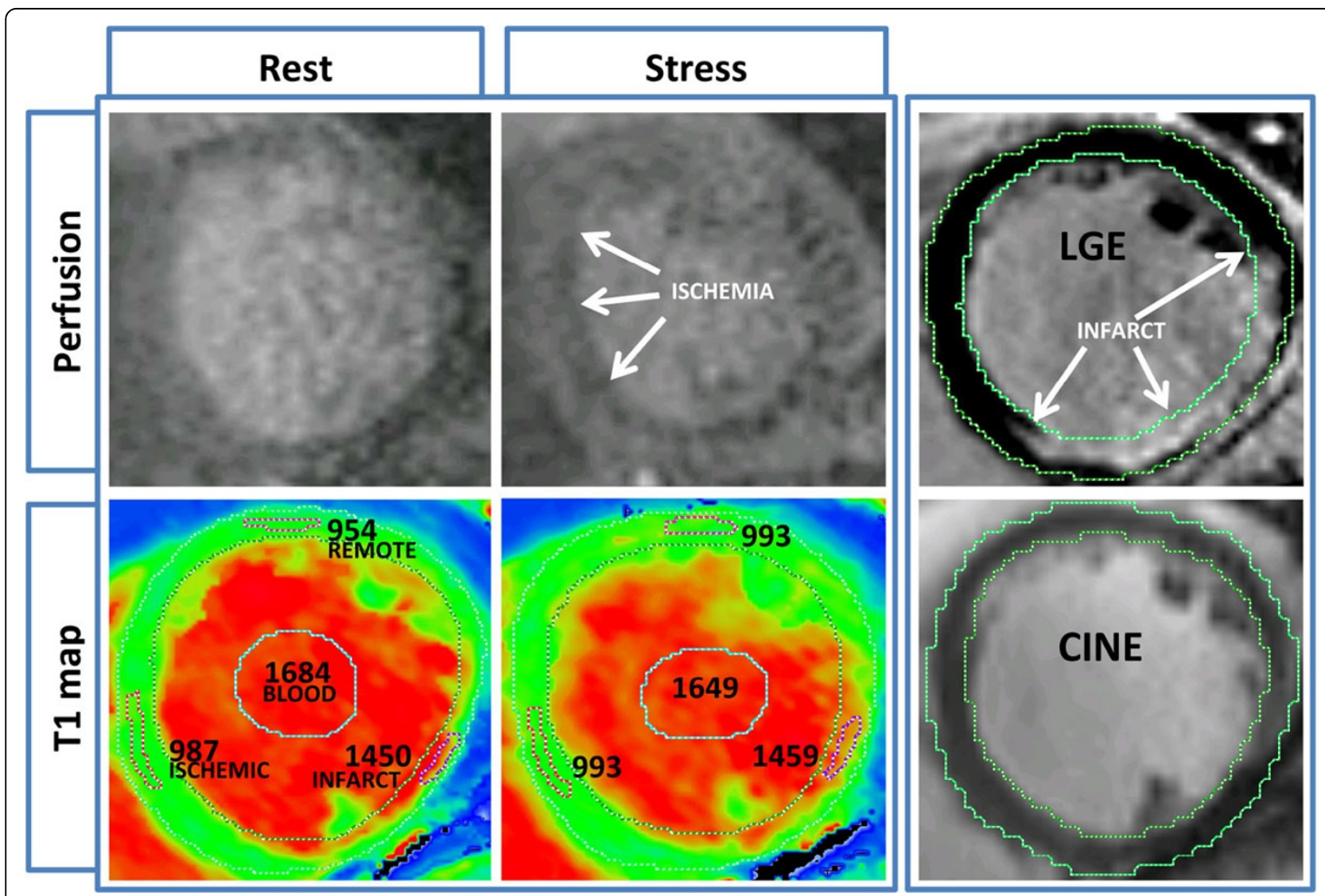

Figure 2 T1-maps at rest and during adenosine stress of a patient with stable coronary artery disease, referenced to stress/rest perfusion, late gadolinium enhancement (LGE) and cine images. Areas of interest are as labelled; all numbers represent mean T1 values (ms). 
characteristic stress/rest T1-profiles. Further investigation of the blunted T1-reactivity in remote (nonischemic/non-infarcted) myocardium of CAD patients, compared to controls, may deepen our understanding of CAD pathophysiology. Stress/rest T1-mapping has the potential to become a powerful diagnostic and risk stratification tool for CAD.

Published: 27 January 2016

doi:10.1186/1532-429X-18-S1-066

Cite this article as: Liu et al:: Adenosine stress and rest T1-mapping differentiates ischemic, infarcted, remote and normal myocardium - a novel gadolinium-free method for ischemia detection with immediate applications in coronary artery disease. Journal of Cardiovascular Magnetic Resonance 2016 18(Suppl 1):O66.

Submit your next manuscript to BioMed Central and take full advantage of:

- Convenient online submission

- Thorough peer review

- No space constraints or color figure charges

- Immediate publication on acceptance

- Inclusion in PubMed, CAS, Scopus and Google Scholar

- Research which is freely available for redistribution

Submit your manuscript at www.biomedcentral.com/submit 